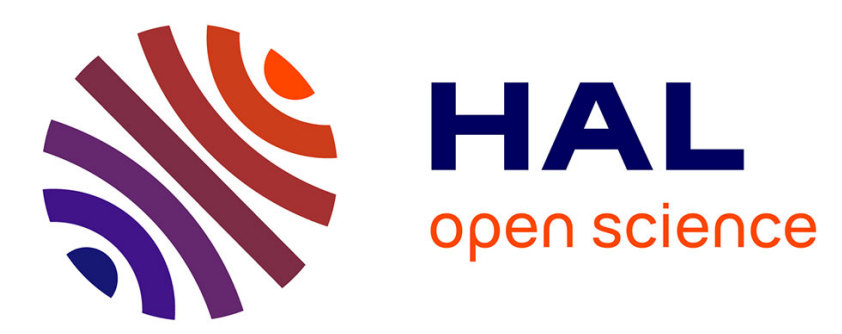

\title{
Two-dimensional electronic properties of the purple potassium molybdenum bronze K0.9Mo6O17
}

R. Buder, J. Devenyi, J. Dumas, J. Marcus, J. Mercier, C. Schlenker, H. Vincent

\section{- To cite this version:}

R. Buder, J. Devenyi, J. Dumas, J. Marcus, J. Mercier, et al.. Two-dimensional electronic properties of the purple potassium molybdenum bronze K0.9Mo6O17. Journal de Physique Lettres, 1982, 43 (2), pp.59-65. 10.1051/jphyslet:0198200430205900 • jpa-00232008

\section{HAL Id: jpa-00232008 https://hal.science/jpa-00232008}

Submitted on 1 Jan 1982

HAL is a multi-disciplinary open access archive for the deposit and dissemination of scientific research documents, whether they are published or not. The documents may come from teaching and research institutions in France or abroad, or from public or private research centers.
L'archive ouverte pluridisciplinaire HAL, est destinée au dépôt et à la diffusion de documents scientifiques de niveau recherche, publiés ou non, émanant des établissements d'enseignement et de recherche français ou étrangers, des laboratoires publics ou privés. 
Classification

Physics Abstracts

$72.15 \mathrm{E}-61.60-65.40 \mathrm{E}$

\title{
Two-dimensional electronic properties of the purple potassium molybdenum bronze $\mathrm{K}_{0.9} \mathrm{Mo}_{6} \mathrm{O}_{17}$
}

\author{
R. Buder, J. Devenyi, J. Dumas, J. Marcus, J. Mercier, C. Schlenker \\ Groupe des Transitions de Phases, C.N.R.S., B.P. 166, 38042 Grenoble Cedex, France \\ and $\mathrm{H}$. Vincent
}

Laboratoire de Cristallographie, C.N.R.S., B.P. 166, 38042 Grenoble Cedex, France

(Reçu le 3 novembre 1981, accepté le 24 novembre 1981)

\begin{abstract}
Résumé. - On a étudié les propriétés électriques et magnétiques entre $2 \mathrm{~K}$ et $300 \mathrm{~K}$, la chaleur spécifique à basse température ainsi que la structure cristallographique à $300 \mathrm{~K}$ de monocristaux de $\mathrm{K}_{0,9} \mathrm{Mo}_{6} \mathrm{O}_{17}$, préparés par réduction électrolytique. Cette étude montre que $\mathrm{K}_{0,9} \mathrm{Mo}_{6} \mathrm{O}_{17}$ est un métal quasi bidimensionnel, ce qui est en bon accord avec les données structurales. La transition observée au-dessous de $120 \mathrm{~K}$ est attribuée à l'ouverture d'un gap partiel à la surface de Fermi, probablement associée à l'apparition d'une onde de densité de charge.
\end{abstract}

\begin{abstract}
The electrical and magnetic properties between $2 \mathrm{~K}$ and $300 \mathrm{~K}$, the low temperature specific heat and the crystal structure at $300 \mathrm{~K}$ have been studied on single crystals of $\mathrm{K}_{0.9} \mathrm{Mo}_{6} \mathrm{O}_{17}$ grown by the electrolytic reduction technique. $\mathrm{K}_{0.9} \mathrm{Mo}_{6} \mathrm{O}_{17}$ is found to be a quasi two-dimensional metal; this is consistent with the structural data. The transition which takes place below $120 \mathrm{~K}$ is due to the partial opening of a gap at the Fermi surface, possibly related to the onset of a charge density wave.
\end{abstract}

1. Introduction. - Among the series of the potassium molybdenum bronzes of general formula $\mathrm{K}_{x} \mathrm{MoO}_{3}$, two compounds have previously been extensively studied; the so-called red bronze $\mathrm{K}_{0.33} \mathrm{MoO}_{3}$ has been shown to be at all temperatures a semiconductor [1]; the blue bronze $\mathrm{K}_{0.30} \mathrm{MoO}_{3}$ exhibits a semiconductor to metal transition at $180 \mathrm{~K}$ and extremely anisotropic, quasi one-dimensional properties in the metallic phase [2, 3, 4]. A third compound, of approximate formula $\mathrm{K}_{0.9} \mathrm{Mo}_{6} \mathrm{O}_{17}$ and with a purple colour, had first been prepared more than ten years ago [5]; but no single crystal of reasonable size had been grown and its physical properties had therefore been hardly studied.

However, while in either the red or the blue bronze, the $4 \mathrm{~d}$ electron concentration brought in by the alcaline metal corresponds on the average to one $4 \mathrm{~d}$ electron per three molybdenum sites, one expects in $\mathrm{K}_{0.9}{ }_{9} \mathrm{Mo}_{6} \mathrm{O}_{17}$ roughly one $4 \mathrm{~d}$ electron per two molybdenum sites. Such a different ratio, in addition to different crystal structures, should make a detailed study of $\mathrm{K}_{0.9} \mathrm{Mo}_{6} \mathrm{O}_{17}$ worthwhile.

We have therefore grown single crystals of $\mathrm{K}_{0.9} \mathrm{Mo}_{6} \mathrm{O}_{17}$ by the electrolytic technique; the 
crystal structure has been refined at $300 \mathrm{~K}$ and has been found different from that of the neighbouring compound $\mathrm{Na}_{0.9} \mathrm{Mo}_{6} \mathrm{O}_{17}$ [6]. The physical properties including electrical transport, magnetic susceptibility and specific heat have been studied between $2 \mathrm{~K}$ and $300 \mathrm{~K}$. We report in this letter that the electrical resistivity is highly anisotropic and characteristic of a two-dimensional metal; these results are well accounted for by the structural data. We also establish the existence of a phase transition below $120 \mathrm{~K}$, reminiscent of the charge density wave transitions well-known in the layered transition metal dichalcogenides and in the one-dimensional systems [7].

2. Experimental techniques. - The single crystals have been grown by the electrolytic reduction of a melt of the potassium molybdate $\mathrm{K}_{2} \mathrm{MoO}_{4}$ and of the oxide $\mathrm{MoO}_{3}$ in the molar ratio 1 to 4.90 . The crystals are purple elongated platelets of typical size $4 \times 2 \times 0.2 \mathrm{~mm}^{3}$.

The crystal symmetry, lattice constants and space group, have been studied by X-ray photographic techniques using a precession camera. The crystal structure has been determined from single-crystal X-ray data collected by an automatic four-circle diffractometer.

The electrical resistivity has been measured between $2 \mathrm{~K}$ and $300 \mathrm{~K}$ by the four contact technique using a gold paste. Thermopower data have been obtained with a slowly alternating temperature gradient, according to the method reported in reference [8]. The thermal and electrical contacts were obtained with copper wires pressed and attached to the sample by indium points. Magnetic susceptibility has been recorded between $2 \mathrm{~K}$ and $300 \mathrm{~K}$ with a vibrating sample magnetometer. The specific heat has been measured on small single crystals between $2 \mathrm{~K}$ and $140 \mathrm{~K}$ with a nicrocalorimeter using a relaxation technique as described elsewhere [9]. The sample-holder is a diamond platelet and the temperature difference between the sample-holder and the reference copper block is measured with an Au-Fe-chromel thermocouple.

3. Results. - The results of the crystal structure determination are only summarized here. A more detailed report will be published separately [10]. The lattice is found hexagonal with $a=5.538(2) \AA$ and $c=13.656(4) \AA$, with one formula $\mathrm{KMo}_{6} \mathrm{O}_{17}$ per unit cell. The $c$-axis is found perpendicular to the plane of the platelets. The symmetry is trigonal and the space group is $\mathbf{P} \overline{3}$. The numbers of independent crystallographic sites are found to be 3 for the molybdenum, 4 for the oxygen and 1 for the potassium ions. The atomic positional parameters are given in table I. One third of the Mo cations, labelled Mo(1), occupy tetrahedral sites, while the Mo(2) and $\mathrm{Mo}(3)$ cations have octahedral surroundings. The $\mathrm{K}$ cations are surrounded by 12 oxygen anions which form icosahedral sites (Fig. 1). This structure is basically different from that of the neighbouring compound $\mathrm{Na}_{0.9} \mathrm{Mo}_{6} \mathrm{O}_{17}$, showing only Mo octahedral sites [6].

The structure can be described as slabs of $\mathrm{ReO}_{3}$-type connected by $\mathrm{KO}_{12}$ icosahedra. Each icosahedron is itself edge-linked to $6 \mathrm{Mo}(1) \mathrm{O}_{4}$ tetrahedra. Each slab is built up of 4 layers of $\mathrm{Mo}(2)$ and $\mathrm{Mo}(3)$ octahedra sharing corners; these layers are parallel to the(001) plane. Two slabs are connected by $\mathrm{K}$ icosahedra which share 2 faces with the upper and lower neighbouring

Table I. - Positional parameters of $\mathrm{K}_{0.9} \mathrm{Mo}_{6} \mathrm{O}_{17}$ at $300 \mathrm{~K}$

\begin{tabular}{llll}
\hline $\mathrm{K}$ & 0 & 0 & $1 / 2$ \\
$\mathrm{Mo}(1)$ & $1 / 3$ & $2 / 3$ & $0.36792(5)$ \\
$\mathrm{Mo}(2)$ & $1 / 3$ & $2 / 3$ & $0.92916(6)$ \\
$\mathrm{Mo}(3)$ & 0 & 0 & $0.21958(6)$ \\
$\mathrm{O}(1)$ & $0.1580(8)$ & $0.8427(8)$ & $0.3264(3)$ \\
$\mathrm{O}(2)$ & $0.1632(7)$ & $0.8368(7)$ & $0.8410(3)$ \\
$\mathrm{O}(3)$ & $1 / 3$ & $2 / 3$ & $0.4927(6)$ \\
$\mathrm{O}(4)$ & $1 / 2$ & 0 & 0 \\
\hline
\end{tabular}




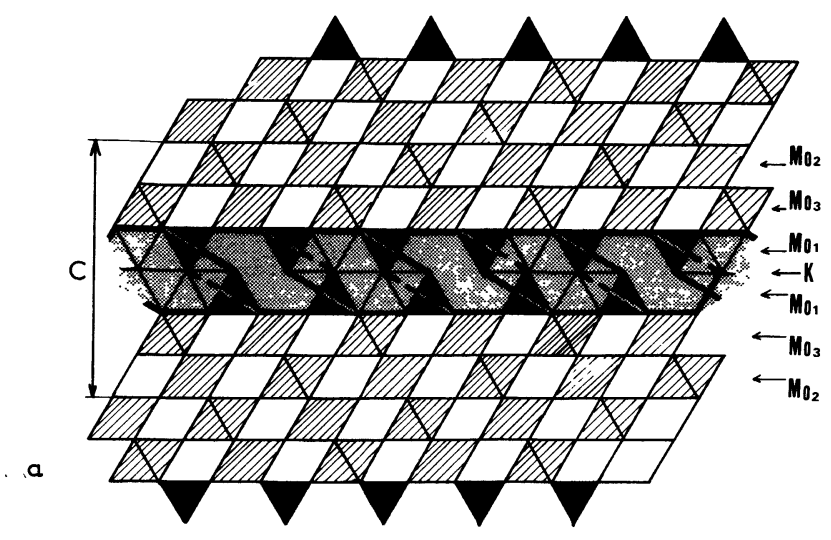

Fig. 1. - Idealized crystal structure of $\mathrm{K}_{0.9} \mathrm{Mo}_{6} \mathrm{O}_{17}$, viewed along the $a$-axis and showing only the oxygen polyhedra containing the Mo or K cations. These polyhedra are located either in a given (120) plane (octahedra with the above edge drawn) or in the neighbouring parallel plane (other octahedra). The Mo(1) sites are inside oxygen tetrahedra (black triangles), the $\mathrm{Mo}(2)$ and $\mathrm{Mo}(3)$ sites inside octahedra (hatched), making two-dimensional infinite layers perpendicular to $c$. The $\mathrm{K}$ sites are in oxygen icosahedra (shown by heavy lines and by dotted ones), separating the octahedra layers.

Mo(3) octahedra. Each $\mathrm{K}$ icosahedron is edge-linked to 3 upper and 3 lower Mo(1) tetrahedra. Each Mo(1) tetrahedron is itself corner-linked to $3 \mathrm{Mo}(3)$ octahedra of the neighbouring layer. There is no Mo(1)-O-Mo(1) bonding, so that the Mo-O-Mo bonding, infinite in the $a$ and $b$ directions, is disrupted in the $c$ direction.

The Zachariasen's bond length-bond strength relation has been fitted on the Mo-O bonds. The computed effective mean Mo valences are +6 on the Mo(1) tetrahedral sites and about 5.1 and 5.8 respectively on the $\mathrm{Mo}(2)$ and $\mathrm{Mo}(3)$ octahedral sites. The $\mathrm{K}$ ions are found to be in $\mathrm{K}^{+}$ states. The refinement is also consistent with a chemical formula close to $\mathrm{K}_{0.9} \mathrm{Mo}_{6} \mathrm{O}_{17}$; this indicates that a non negligible fraction of the $\mathrm{K}$ sites are not occupied.

The electrical resistivity $\rho$ has been measured both in the plane of the sample $(\perp c)$ and along the $c$-axis. In the first case, the two current contacts covered the ends of the sample. In the second case $(/ / c)$, they were attached to both faces of the crystal; the measurements, performed as described in reference [11], give in this case only correct orders of magnitude for $\rho$. Typical data are plotted $v s$. temperature on figure 2. $\rho$ is found strongly anisotropic, roughly 500 times higher along the $c$-axis than in the plane $\perp c$; it decreases linearly with temperatures below $300 \mathrm{~K}$ down

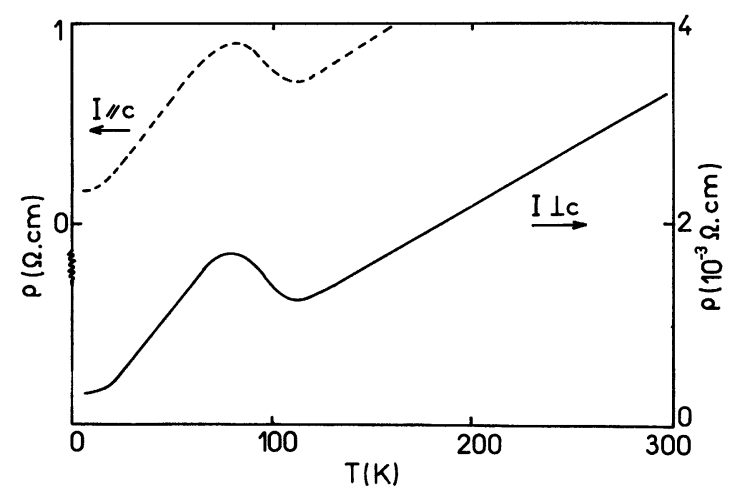

Fig. 2. - Electrical resistivity $v s$. temperature. $I \perp c$ (full curve); $I / / c$ (dotted curve). Note the change of the vertical scale between the two curves. 
to $\sim 110 \mathrm{~K}$; below $110 \mathrm{~K}$ it shows a bump with a maximum at $70 \mathrm{~K}$. The residual resistivity is $\sim 3 \times 10^{-4} \Omega$.cm in the plane $\perp c$ and $\sim 0.2 \Omega$.cm along $c$.

The thermopower measured with a temperature gradient in the plane $\perp c$ is shown $v s$. temperature on figure 3 ; it is small and negative above $120 \mathrm{~K}$, roughly proportional to temperature above $150 \mathrm{~K}$, and $\sim-20 \mu \mathrm{V} / \mathrm{K}$ at $300 \mathrm{~K}$; it is positive below $120 \mathrm{~K}$ and shows a maximum of $\sim 70 \mu \mathrm{V} / \mathrm{K}$ at $70 \mathrm{~K}$.

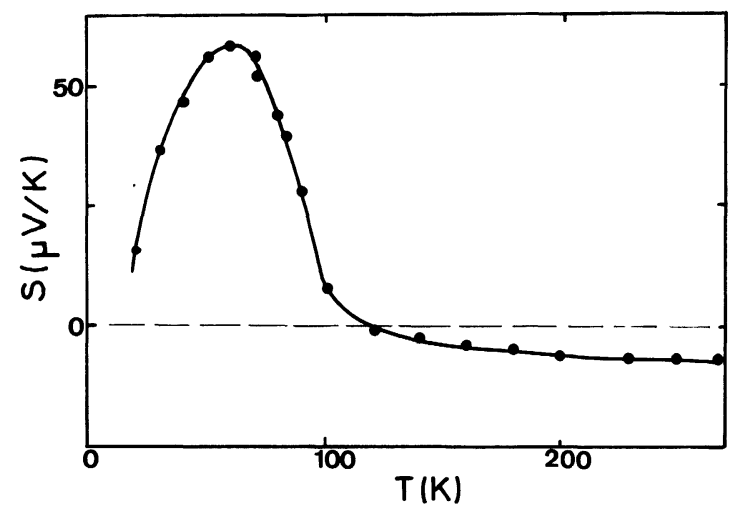

Fig. 3. - Thermopower $v s$. temperature measured with a temperature gradient perpendicular to $c$.

Figure 4 shows the magnetic susceptibility $\chi v s$. temperature both for magnetic field applied along $c$ and in the basal plane; $\chi$ is found temperature-independent and isotropic above $120 \mathrm{~K}$. Below $120 \mathrm{~K}$, it becomes strongly anisotropic; for $H \perp c$, it decreases slowly with temperature; for $H / / c$, it shows a minimum at $\sim 80 \mathrm{~K}$ and an anomalous behaviour below $10 \mathrm{~K}$.

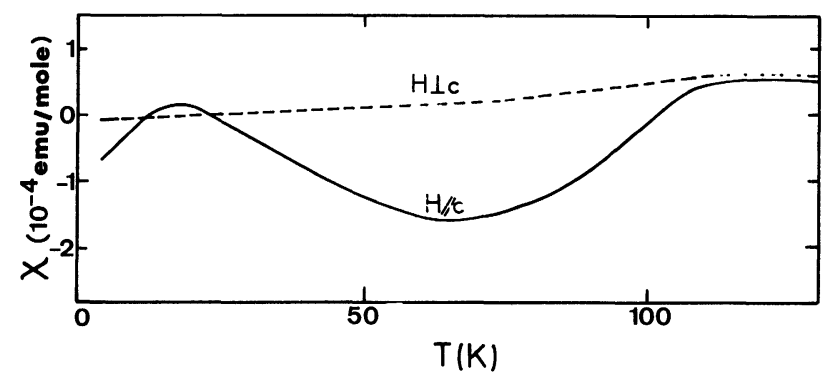

Fig. 4. - Magnetic susceptibility $v s$. temperature; the absolute values of $\chi$ are known with an accuracy of $5 \times 10^{-5} \mathrm{emu} / \mathrm{mole}$.

The specific heat data obtained between $2 \mathrm{~K}$ and $5 \mathrm{~K}$ are shown on figure 5 as a plot of $C_{p} / T$ vs. $T^{2}$; in this temperature range $C_{p}$ obeys the law :

$$
C_{p}=\gamma T+\beta T^{3}
$$

with

$$
\begin{aligned}
& \gamma=1.6 \pm 0.2 \mathrm{~mJ} \cdot \mathrm{mole} \mathrm{e}^{-1} \cdot \mathrm{K}^{-2} \\
& \beta=1.2 \pm 0.1 \mathrm{~mJ} \cdot \mathrm{mole}{ }^{-1} \cdot \mathrm{K}^{-4}
\end{aligned}
$$

The $\beta$-value corresponds to a Debye temperature $\theta_{\mathrm{D}}=340 \pm 10 \mathrm{~K}$. 


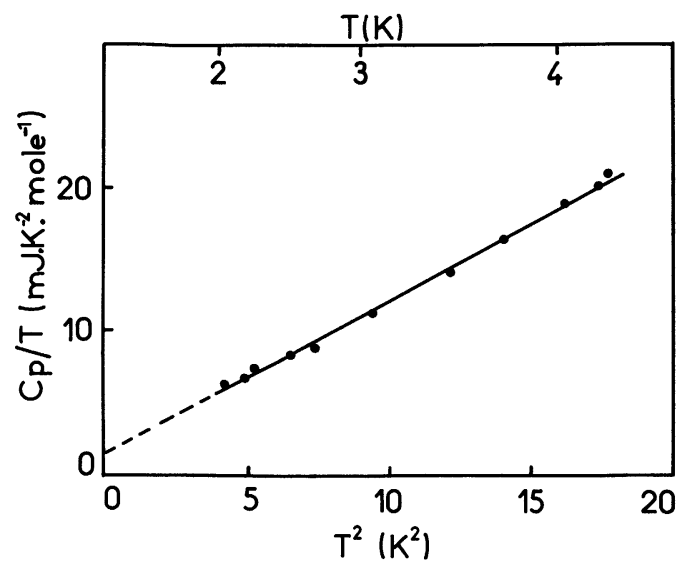

Fig. 5. - Low temperature specific heat plotted as $C_{p} / T$ vs. $T^{2}$.

4. Discussion. - The collected results establish clearly that the purple bronze $\mathrm{K}_{0.9} \mathrm{Mo}_{6} \mathrm{O}_{17}$ shows both two-dimensional electrical properties and a phase transition below $120 \mathrm{~K}$. The transport properties below $120 \mathrm{~K}$ are similar to what is found for example in the layered dichalcogenide $\mathrm{TiSe}_{2}$ [12] or in the quasi one-dimensional compound $\mathrm{NbSe}_{3}$ [13] ; the properties of these compounds are well accounted for by the presence of charge density waves.

The structural data corroborate that the alcaline metal has given its outer electron to the transition metal cation; the transport properties are therefore due to the $4 \mathrm{~d}$ Mo states. The crystal structure, showing infinite layers of $\mathrm{MoO}_{6}$ octahedra separated by the $\mathrm{K}^{+}$ions and by the $\mathrm{MoO}_{4}$ tetrahedra, is then consistent with the two-dimensional electronic properties, since the Mo in the tetrahedral sites have a $6+$ charge and no $4 \mathrm{~d}$ electron and since the $4 \mathrm{~d}$ electrons are located on the $\operatorname{Mo}(2)$ and predominantly on the $\operatorname{Mo}(3)$ sites in the two-dimensional infinite layers. As the crystal structure does not allow any direct overlap between the $4 \mathrm{~d}$ wavefunctions, the conduction band is expected to be, as for example in $\mathrm{K}_{0.30} \mathrm{MoO}_{3}$, an antibonding $\pi^{*}$ band resulting from the hybridization between $t_{2 \mathrm{~g}} 4 \mathrm{~d}$ and oxygen $\mathrm{p}_{\pi}$ states [14]; it should be only weakly filled with an average of $0.54 \mathrm{~d}$ electron per molybdenum. The structural properties should then lead to a very anisotropic Fermi surface. It should be pointed out that the crystal structure in $\mathrm{K}_{0.9} \mathrm{Mo}_{6} \mathrm{O}_{17}$ does not show any evidence of a very weak chemical bond along the $c$-axis between the infinite $\mathrm{MoO}_{6}$ layers; the structure is therefore three-dimensional and not similar to that of the so-called layered materials with weak bonds, usually of the Van der Waals type between the layers [12]. However, the electronic properties are in our case two-dimensional, as a consequence of the spatial separation between the $\mathrm{Mo}^{6+}$ on tetrahedral sites and the other Mo cations on octahedral sites.

The negative thermopower above $150 \mathrm{~K}$ indicates that at high temperature the dominant carriers are electrons and that the Fermi surface should show mainly electron pockets. As the thermopower $S$ is roughly proportional to $T$ in this temperature range, one can estimate in a first approximation the density of states at the Fermi level $g\left(E_{\mathrm{F}}\right)$, from the relation :

$$
S=\frac{2 \pi^{2}}{9} \frac{k_{\mathrm{B}}^{2}}{e} g\left(E_{\mathrm{F}}\right) T
$$

where $k_{\mathrm{B}}$ is the Boltzmann constant and $e$ the electron charge. One obtains a value for $g\left(E_{\mathrm{F}}\right)$ of $1.7 \pm 0.1 \mathrm{eV}^{-1}$ per $\mathrm{K}_{0.9} \mathrm{Mo}_{6} \mathrm{O}_{17}$ molecule; this should correspond to a rather broad band.

The transition taking place below $120 \mathrm{~K}$ is very likely due to a partial opening of a gap at the Fermi surface which leads to a change in the concentrations of both types of carriers, electrons 
and holes; this could be due to a charge density wave. The thermopower which becomes positive shows that the dominant carriers are holes at $T<120 \mathrm{~K}$. The increase in the electrical resistivity indicates that the resulting carrier concentration is smaller at low temperature. From the resistivity data and in a very crude model assuming that the mobility is the same for both types of carriers and does not change at the transition, one may estimate the decrease of the carrier concentration at low temperature; the resistivity measured at $80 \mathrm{~K}$ is found to be $\sim 1.8 \times 10^{-3} \Omega$.cm, while the value extrapolated from the linear high temperature curve would be $0.85 \times 10^{-3} \Omega . \mathrm{cm}$; this would correspond to a decrease of roughly $50 \%$ of the carrier concentration at the transition.

The low temperature specific heat shows clearly a contribution proportional to $T$ which has to be attributed to the charge carriers. The $\gamma$-value of $1.6 \pm 0.2 \mathrm{~mJ} . \mathrm{K}^{-2}$ corresponds in a free electron model to a density of states at the Fermi level of $0.7 \pm 0.1 \mathrm{eV}^{-1}$ per molecule. This result compared to the high temperature value of $1.7 \pm 0.1 \mathrm{eV}^{-1}$ per molecule obtained from the thermopower is also consistent with a decrease of the density of states at the Fermi level taking place at the transition.

The Debye temperature of $340 \mathrm{~K}$ is similar to what is found in other Mo bronzes; in $\mathrm{K}_{0.30} \mathrm{MoO}_{3}$, we have also reported a value of $340 \mathrm{~K}$ [14]. This probably indicates that in these compounds the lattice properties are determined to a large extent by the $\mathrm{MoO}_{6}$ octahedra.

The magnetic susceptibility should be analysed in terms of three contributions :

$$
\chi=\chi_{\text {dia }}+\chi_{\text {orb }}+\chi_{\text {Pauli }}
$$

$\chi_{\mathrm{dia}}$ is the core diamagnetism susceptibility, $\chi_{\text {orb }}$ the orbital contribution which is expected to be of Van Vleck type and $\chi_{\text {Pauli }}$ the conduction electrons term. One may calculate $\chi_{\text {dia }}$ as the superposition of the diamagnetic susceptibility of $\mathrm{K}^{+}, \mathrm{Mo}^{6+}, \mathrm{Mo}^{5+}$ and $\mathrm{O}^{2-}$ ions, in proportions corresponding to the chemical formula; with the data given in reference [15]; this leads to a value : $\chi_{\text {dia }}=-2.74 \times 10^{-4} \mathrm{emu} / \mathrm{mole}$. The resulting orbital and Pauli susceptibilities are then expected to be in the range 1 to $3 \times 10^{-4} \mathrm{emu} / \mathrm{mole}$ depending on the temperature and on the magnetic field orientation. However, the values of $g\left(E_{\mathrm{F}}\right)$ estimated as $1.6 \mathrm{eV}^{-1} /$ molecule in the high temperature and $0.7 \mathrm{eV}^{-1} /$ molecule in the low temperature phase would correspond to Pauli susceptibilities of $\sim 0.5 \times 10^{-4}$ and $0.2 \times 10^{-4} \mathrm{emu} / \mathrm{mole}$ respectively; this shows that the orbital contribution is much larger than the Pauli one. This orbital contribution may be responsible for the anisotropy of $\chi$; one should also notice that the opening of a gap at the Fermi surface should induce an extra orbital contribution in the low temperature phase [16]; but in the absence of any detailed information concerning the band structure of $\mathrm{K}_{0.9} \mathrm{Mo}_{6} \mathrm{O}_{17}$, it is not possible to discuss these data further. One should however mention that the anomalous behaviour of $\chi$ at low temperature may suggest also the existence of a spin density wave.

5. Conclusion. - We have shown in this letter that $\mathrm{K}_{0.9} \mathrm{Mo}_{6} \mathrm{O}_{17}$ is a quasi two-dimensional metal, although the crystal structure is not two-dimensional. The low dimensional electronic properties are a consequence in this compound of the spatial separation between the $\mathrm{Mo}^{6+}$ and $\mathrm{Mo}^{5+}$ ions, the $\mathrm{Mo}^{5+}$ and therefore the $4 \mathrm{~d}$ electrons being located in two-dimensional infinite layers. We propose that the phase transition taking place below $120 \mathrm{~K}$ is due to a partial opening of a gap at the Fermi surface, possibly related to the existence of a charge density wave. Structural studies which could corroborate this model are presently in progress.

Acknowledgments. - The authors whish to thank R. Brusetti for preliminary conductivity measurements on $\mathrm{K}_{0.9} \mathrm{Mo}_{6} \mathrm{O}_{17}$ and $\mathrm{C}$. Escribe-Filippini and $\mathrm{K}$. Konaté for their contribution to the specific heat data. 


\section{References}

[1] Bouchard, G. H., Perlstein, J. H. and Sienko, M. J., Inorg. Chem. 6 (1967) 1682.

[2] Fogle, W. and Perlstein, J. H., Phys. Rev. B 6 (1972) 1402.

[3] Brusetti, R., Chakraverty, B. K., Devenyi, J., Dumas, J., Marcus, J. and Schlenker, C., Recent developments in Condensed Matter Physics, Vol. 2 (Plenum Press), to be published.

[4] Travaglini, G., Wachter, P., Marcus, J. and Schlenker, C., Solid State Commun. 37 (1981) 599.

[5] Réau, J. M., Fouassier, C. and Hagenmuller, P., J. Solid State Chem. 1 (1970) 326.

[6] Stephenson, N. C., Acta Crystallogr. 20 (1966) 59.

[7] See for example : Friend, R. H. and Jérôme, D., J. Phys. C : Solid State Phys. 12 (1979) 1441.

[8] Chaikin, P. M. and FWaK, J. F., Rev. Sci. Instrum. 46 (1975) 218.

[9] Harper, J. M. E., Geballe, T. H. and Di Salvo, F. J., Phys. Rev. B 15 (1977) 2943.

[10] Vincent, H., Ghedira, M., Marcus, J., Mercier, J. and Schlenker, C., submitted to J. Solid State Chem.

[11] Hambourger, P. D., Phys. Rev. B 15 (1977) 1640.

[12] See for example : Lévy, F. and Froideveaux, Y., J. Phys. C : Solid State Phys. 12 (1979) 473.

[13] See for example : Monceau, P., XVI Int. Conf. on Low Temperature Phys., Los Angeles, Cal. (Aug. 1981), to be published.

[14] Buder, R., Dumas, J., Marcus, J., Mercier, J. and Schlenker, C., Congrès de la Société Française de Physique, Clermont-Ferrand (1981).

[15] Selwood, P. W., Magnetochemistry (Interscience Publ., New York) 1964, p. 78.

[16] Boriack, M. L., Phys. Rev. B 21 (1980) 4478. 